\title{
A comparison of educational strategies for the acquisition of nursing student's performance and critical thinking: simulation-based training vs. integrated training (simulation and critical thinking strategies)
}

Nahid Zarifsanaiey ${ }^{1 *}$, Mitra Amini ${ }^{2}$ and Farideh Saadat ${ }^{3}$

\begin{abstract}
Background: There is a need to change the focus of nursing education from traditional teacher-centered training programs to student-centered active methods. The integration of the two active learning techniques will improve the effectiveness of training programs. The objective of this study is to compare the effects of the integrated training (simulation and critical thinking strategies) and simulation-based training on the performance level and critical thinking ability of nursing students.

Methods: The present quasi-experimental study was performed in 2014 on 40 students who were studying practical nursing principles and skills course in the first half of the academic year in Shiraz University of Medical Sciences. Students were randomly divided into control $(n=20)$ and experimental $(n=20)$ groups.

After training students through simulation and integrated education (simulation and critical thinking strategies), the students' critical thinking ability and performance were evaluated via the use of California Critical Thinking Ability Questionnaire B (CCTST) and Objective Structured Clinical Examination (OSCE) comprising 10 stations, respectively. The external reliability of the California Critical Thinking questionnaire was reported by Case B.to be between 0.78 and 0.80 and the validity of OSCE was approved by 5 members of the faculty. Furthermore, by using Split Half method (the correlation between odd and even stations), the reliability of the test was approved with correlation coefficient of 0.66 . Data were analyzed using t-test and Mann-Whitney test. A significance level of 0.05 was considered to be statistically significant.

Results: The mean scores of the experimental group performance level were higher than the mean score of the control group performance level. This difference was statistically significant and students in the experimental group in OSCE stations had significantly higher performance than the control group $(P<0.001)$. However, the mean scores obtained for the critical thinking did not increase before and after the intervention.

Conclusion: The results showed that, the students' performance level was increased by the application of integrated training (simulation and critical thinking strategies).
\end{abstract}

Keywords: Simulation, Critical Thinking Strategies

\footnotetext{
* Correspondence: nzarifsanaee@gmail.com

'Department of E-learning, Virtual School, Center of Excellence for e-Learning

in Medical Sciences, Shiraz University of Medical Sciences, Shiraz, Iran

Full list of author information is available at the end of the article
} 


\section{Background}

Technical and treatment advancements and rapid changes of political, social and cultural factors demonstrate the need to use new active training strategies in medical and nursing education. The nursing students should be actively trained in order for them to sufficiently understand real clinical situations and gain the learning in a real context $[1,2]$. Deubel stated that the use of an educational theory and subsequent use of a teaching model alone is not sufficient to advance learning and in order to design active courses and create the ground for learners to think, educational spectrum and teaching models must be integrated. The integration of these practices such as simulation and critical thinking strategies will improve the effectiveness of training programs and will help students gain Nursing skills [3].

Students have interest in simulation as one of the forms of interactive learning as well as a powerful way of transferring skills, which can be performed individually or in small groups. There are many types of simulation such as live simulation, virtual simulation, structural simulation, role-playing simulation and use of mannequins $[4,5]$. Simulation helps students to understand the importance of nursing interventions to patient outcomes by reflecting on the performance [6,7]. It was revealed in different studies that simulation strengthens confidence, interest and clinical skills in nursing students [8]. Nursing students should be active learners and think critically to provide safe patient care. Hence, nursing education has stressed critical thinking as a necessary nursing skill [4].

Critical thinking is an essential component of professional responsibility and quality nursing care. In nursing, critical thinking is the ability to think systematically and reflect on the reasoning process used to ensure safe nursing practice [9]. Therefore, critical thinking skills are helpful in making appropriate decisions and quality nursing care. The development of critical thinking strategies and activities that facilitate this process will assist nurse instructors in planning appropriate educational strategies and assessment techniques. Simpson et al. believe that, critical thinking practices can change the students' focus from remembering to active learning [10]. Critical thinking strategies are the active learning strategies to promote critical thinking.

There are many educational methods for improving critical thinking such as using problem-based learning with case studies, group discussion and self reflection [11].

There is a close correlation between the simulation-based learning, critical thinking strategies and the principles of constructivist and collaborative learning. Furthermore, the integration of these strategies will strengthen learning [12], because students focus on problems in real clinical situations that could strengthen their understanding of concept and prepare them to manage complex clinical situations $[6,13]$. One of the major problems in training the nursing students is the utilization of traditional and nonactive education in the clinical training and practical skills, which makes it difficult for the students to follow the critical thinking, problem solving ability and clinical decision path $[13,14]$. One of the problems for the nurse instructors is the implementation of critical thinking strategies in the curriculum and scenarios, which determine the clinical complications in making the right decisions for the patient [14].

In most reviewed studies, the integrated simulation training was investigated only with Problem based learning and the use of other critical thinking strategies (problem solving-based on group discussion) is less studied. The importance and necessity of this study is clear with respect to the special status of teaching the critical thinking skills, the sensitivity of teaching the clinical skills. In this way, we can empower nurses by adopting new techniques and strategies of active learning. Therefore, the aim of this study is to compare the effects of integrated training (simulation and critical thinking strategies) and simulation-based training on the performance level and the critical thinking ability of students in 2014 in Shiraz.

\section{Methods}

\section{Study design}

This research was a quasi-experimental research with non-equivalent group pretest posttest design, which was carried out to compare the effect of simulation-based training and integrated training (simulation and critical thinking strategies) on the performance level and the critical thinking ability of nursing students studying at Shiraz Faculty of Nursing and Midwifery in 2014.

\section{Samples and setting}

The study samples include all first-year nursing students studying in the second semester of the academic year of 2014-2015 $(n=40)$ who were selected applying census method. In other words, the sample size is equal to the size of the population studied.

\section{Participants \\ Selection criteria}

All students who took the 2-credit course of principles and practical nursing skills and wished to participate in the study were included.

Students who were enrolled as guest students at the semester and had no desire to participate in the research were excluded.

All the study subjects were divided into two groups according to age, sex, place of residence, and diploma average. Thereafter, two groups were randomly selected 
as the experimental group $(n=20)$ and the control group $(n=20)$.

\section{Implementation stages of the research}

1. Before the training, the level of critical thinking skills of both groups was investigated.

2. Two teaching techniques were carried out in each group. The experimental and intervention groups were trained using the integrated and simulationbased techniques, respectively.

Experimental group The experimental group was trained for ten 2-h sessions using critical thinking strategies along with simulation.

The critical thinking strategies in this research include problem based learning with small group discussion

At each session, hypothetical scenarios of clinical conditions related to the subject matter, prepared utilizing patient records in hospitals and reference books containing clinical setting and strategic questions, were discussed.

Then, the solution to the problem was determined by students in small group discussion after changing the learning environment and the manner of seats arrangement in the lab in a $U$ shape.

At this stage, the instructor was used as a facilitator and provided students with the necessary instructions and tried to encourage all students to participate in the discussion.

\section{2- Simulation stage (role-playing and mannequins):}

Then the students were taught the basic instruction by the instructor through role-playing, and they were also encouraged by the instructor to practice in groups of ten on the mannequins (Fig. 1).

Control group The simulation method alone was used in the control group in such a way that the related instructor taught the subject matter of the same session on the mannequins through role-playing, without any clinical background and students practiced in groups of 10 .

3. At the end of the program, both groups participated in the critical thinking skills test and Objective Structured Clinical Examination (OSCE) test in order to measure their performance. OSCE test was carried out by planning 10 stations.

\section{Data collection tool}

The tool used in measuring the critical thinking ability was the California Critical Thinking Skills Test Form B (CCTST). This tool was developed to measure students'

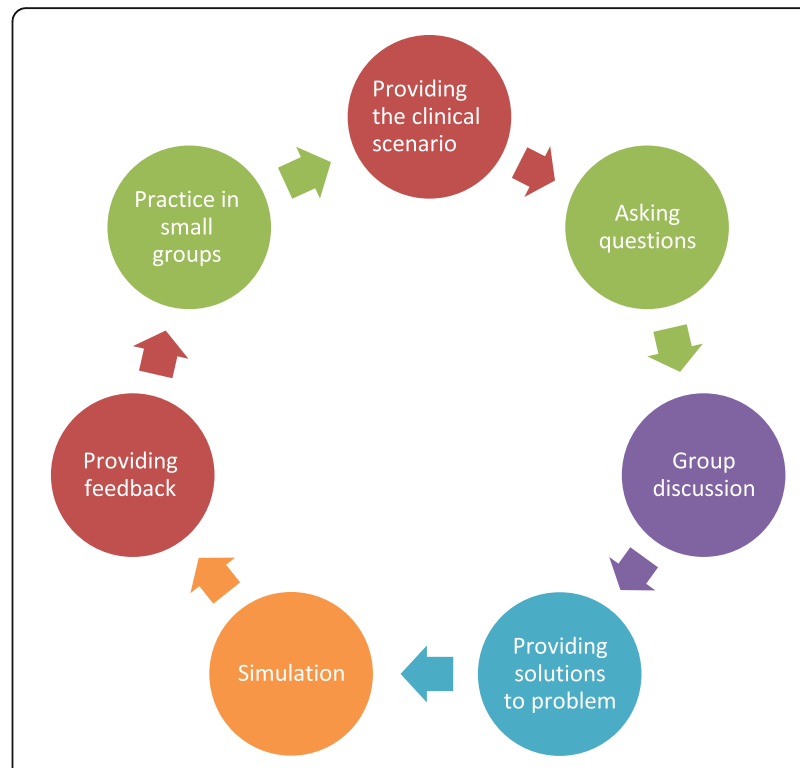

Fig. 1 Integration cycle of the simulation and critical thinking strategies

critical thinking skills and it contains 34 multiple-choice questions, designed in five areas of cognitive skills of critical thinking, which include analysis, inference, inductive reasoning, deductive reasoning and evaluation. Each person was awarded one score for each question which was answered correctly in the questionnaire and the total of correct answers constitutes the total score, the minimum and maximum of which were 0 and 34 . Scores obtained in each section of the test was between the range of 0 and 16, such that in the analysis, inference, evaluation, inductive reasoning and deductive reasoning sections, 9, 11, 14, 16 and 14 scores were considered, respectively.

Objective Structured Clinical Examination (OSCE) test questions were utilized as a tool to assess the students' performance. This test was selected from 10 stations, including measuring blood pressure, dressing change, measuring body temperature, colostomy care, wound care clinical scenario, clinical bowel care scenario, pressure ulcer care, oxygen therapy, vital signs scenario, identifying devices by consulting with nursing team members.

Validity and reliability of tools The external reliability of the California Critical Thinking Skills Test Form $\mathrm{B}$ (CCTST) was measured by Facione to be between 0.78 to 0.80 using the Kuder-Richardson formula 20 (KR-20) [15].

Objective Structured Clinical Examination (OSCE) validity was measured based on the content validity by five members of the faculty. Furthermore, the reliability of the test was approved with correlation coefficient of 0.66 
Table 1 Comparison of mean and standard deviation of critical thinking score in the experimental and control groups before and after intervention

\begin{tabular}{lccccc}
\hline Critical Thinking Score & \multicolumn{2}{l}{ Mean and Standard Deviation } & & Df & \\
\cline { 2 - 5 } Educational groups & Before Intervention & After Intervention & & \\
\hline Experimental group & $11.10 \pm 3.47$ & $10.95 \pm 3.15$ & 0.206 & 38 & 0.838 \\
Control group & $9.5 \pm 2.56$ & $9.10 \pm 3.27$ & 0.206 & 36.08 & 0.838 \\
\hline
\end{tabular}

using Split Half technique (the correlation between odd and even stations).

\section{Statistical analysis}

Data were collected and imported into SPSS.V.15. Thereafter, they were analyzed and evaluated using descriptive and analytic statistics. The mean scores obtained from the performance level of the two groups were compared using the independent $t$-test, after the intervention. The pair $t$-test was utilized to compare the mean scores for critical thinking before and after the intervention. In addition, Mann-Whitney test and chi-square test were utilized to compare different fields of the critical thinking.

A significant level of $\mathrm{P}<0.05$ was considered to be statistically significant.

\section{Study challenges}

One of the major limitations of this study was the presence of both groups of students in a collaborative learning environment. In addition, the implementation time of the training program of both groups was different due to less interaction between the two groups. Another limitation of this study was lack of educational sessions. Moreover, there was no possibility to hold more sessions in the curriculum of the faculty as a result of the coincidence of class hours.

\section{Results}

Among the 40 first-semester nursing students who participated in the study, 25 were females (62.5\%) while 15 were males $(37.5 \%)$. There was a total of 13 female (65\%) and 7 male students (35\%) in the experiment. Moreover, there was a total of 12 female (60\%) and 8 male students $(40 \%)$ in the control group. The "Chi- square" test showed that the subjects in both experimental and control groups were homogenous in terms of sex. The mean age in the experimental group $(19.75 \pm 1.16)$ and in the control group $(16.70 \pm 1.16)$ was not significantly different ( $p=0.909)$. Furthermore, the average GPA in the experimental group $(18.14 \pm 1.22)$ and in the control group $(17.87 \pm 1.80)$ was not significantly different $(P=0.597)$. In addition, there were 15 students $(75 \%)$ and 5 students $(25 \%)$ in the experimental group who were respectively living on and off campus. Moreover, in the control group, there were 17 students (85\%) and 3 students (15\%) who were living on and off campus. Using "Chi square" test, the frequency distribution of accommodation shows that there is homogeneity between the two groups.

The first hypothesis of the research states that "the integrated training (simulation and critical thinking strategies), compared with simulation training, improves students' performance." For this reason, the mean and standard deviation of the critical thinking score was evaluated in experimental and control groups before and after the intervention (Table 1).

As shown in Table 1, there was no increase in the average scores of the critical thinking sub-groups before and after the intervention and the use of both the integrated strategies and the simulation-based training (critical thinking and simulation) methods alone didn't improve the critical thinking ability. Furthermore, the critical thinking sub-groups were studied in two groups before (Table 2) and after the intervention (Table 3).

It was shown in Table 3 that, the average scores of the critical thinking in sub-groups of evaluation, inference, deductive and inductive reasoning were not statistically

Table 2 Comparison of mean and standard deviation of critical thinking subgroups scores in both groups before the intervention

\begin{tabular}{|c|c|c|c|c|c|}
\hline \multirow{2}{*}{$\begin{array}{l}\text { Educational groups } \\
\text { Critical Thinking Score }\end{array}$} & \multicolumn{2}{|c|}{ Mean and Standard Deviation } & \multirow[t]{2}{*}{$T$ test } & \multirow[t]{2}{*}{ Df } & \multirow[t]{2}{*}{ Sig } \\
\hline & Before Intervention & After Intervention & & & \\
\hline Analysis & $3.20 \pm 1.39$ & $2.90 \pm 1.02$ & 0.775 & 38 & 0.509 \\
\hline Evaluation & $4.15 \pm 1.89$ & $3.10 \pm 1.80$ & 1.793 & 38 & 0.589 \\
\hline Inference & $3.75 \pm 1.80$ & $3.50 \pm 1.46$ & 0.481 & 38 & 0.721 \\
\hline Deductive reasoning & $5.80 \pm 2.33$ & $5.60 \pm 2.08$ & 0.286 & 38 & 0.223 \\
\hline Inductive reasoning & $3.95 \pm 2.50$ & $3.00 \pm 2.1$ & 1.300 & 38 & 0.803 \\
\hline
\end{tabular}


Table 3 Comparison between the mean and standard deviation of critical thinking sub-group scores in the training groups after the intervention

\begin{tabular}{|c|c|c|c|c|c|}
\hline \multirow{2}{*}{$\begin{array}{l}\text { Educational groups } \\
\text { Critical Thinking Score }\end{array}$} & \multicolumn{2}{|c|}{ Mean and Standard Deviation } & \multirow[t]{2}{*}{$T$ test } & \multirow[t]{2}{*}{ Df } & \multirow[t]{2}{*}{ Sig } \\
\hline & Before Intervention & After Intervention & & & \\
\hline Analysis & $2.8 \pm 1.87$ & $1.85 \pm 1.56$ & 1.884 & 38 & 0.228 \\
\hline Evaluation & $4.05 \pm 2.25$ & $4.15 \pm 1.53$ & -0.164 & 38 & 0.694 \\
\hline Inference & $4.05 \pm 1.43$ & $3.10 \pm 1.73$ & 1.903 & 38 & 0.622 \\
\hline Deductive reasoning & $5.75 \pm 2.02$ & $5.30 \pm 2.12$ & 0.685 & 38 & 0.753 \\
\hline Inductive reasoning & $4 \pm 1.39$ & $3.50 \pm 2.10$ & 0.893 & 38 & 0.860 \\
\hline
\end{tabular}

significant after the intervention in both experimental and control groups. However, Mann-Whitney test showed that there was a significant difference between the groups in the analysis dimension after the intervention (Table 4).

As can be seen in Table 4, the Mann-Whitney test showed that the mean score of the critical thinking in the analysis dimension in the experimental group was higher than the mean score of the critical thinking in the analysis dimension in the control group, after the intervention, which was statistically significant.

The second hypothesis states that, the "integrated training (simulation and critical thinking strategies) compared with the simulation-based training improves students' performance." The mean and standard deviation of scores in OSCE (the performance level) were compared in 10 stations in both groups (Table 5).

Total scores were obtained in OSCE test which consisted of 10 stations with 10 scores. In stations $1,2,4,6,7,8,9$ and 10 , the average scores of the experimental group were higher than the average scores of the control group, where the difference was statistically significant at three stations of 2, 6 and 9. The scores obtained at stations 7 and 10 that were not normally distributed, were analyzed using nonparametric Mann-Whitney test. Here, the station 7 was statistically significant $(p=0.052)$. The average scores of both groups were equal at station 3. Furthermore, at station 5, the average scores of the experimental group were higher than the control group, which was not statistically significant. Generally, the average scores of the performance level of the experimental group were higher than the control group, which was statistically significant (Table 6).

In total, the results showed that the experimental group obtained higher performance score, with statistically significant difference, than the control group $(p=0.001)$.

\section{Discussion}

The aim of this study was to compare the effects of the integrated training (simulation and critical thinking strategies) and simulation-based training on the performance level and critical thinking ability of nursing students. The results of this study showed that the performance level of students in the experimental group (the integrated training) was higher than the performance level of students in the control group (simulation-based training) $(p<0.001)$. Also, the results showed that the score of the critical thinking ability obtained in the integrated training was increased only in the analysis dimension. In other words, this training method didn't fully strengthen students' critical thinking ability. This finding is in line with similar results regarding the effects of the simulated patient (high-fidelity) [16, 17], effect of lecture method alone, lecture and case study, and the simulated patient [14] on critical thinking of nursing students. The results showed that, the critical thinking scores were improved, but there were no significant difference between groups. In summary, it can be concluded that a training course alone is not significantly correlated with the critical thinking. Furthermore, acquiring the critical thinking skills needs long period of time and continuing education. Moreover, the results showed that there was a significant relationship between the score of the performance level of the group which received simulation-based training alone and the one, which received the integrated training (simulation and critical thinking strategy) $(P<0.001)$. The result shows that integrated use of the training methods leads to higher performance in students. Previous studies have also revealed similar results regarding the positive effect of using integrated methods on clinical practice, problem solving skill, clinical efficacy and academic achievement and clinical competency. Moreover, in a study carried out

Table 4 Mean and standard deviation of critical thinking score in the analysis dimension in the experimental and control groups after the intervention

\begin{tabular}{lccc}
\hline Critical Thinking Score in the analysis dimension & $\begin{array}{l}\text { Mean and } \\
\text { Standard Deviation }\end{array}$ & $\begin{array}{l}\text { Mann-Whitney } \\
\text { test }\end{array}$ & $Z$ \\
Educational Groups & $2.85 \pm 1.78$ & 117 & -2.33 \\
\hline Experimental group & $1.85 \pm 1.56$ & & 0.020 \\
Control group & & \\
\hline
\end{tabular}


Table 5 Comparison between the mean and standard deviation of scores obtained from OSCE test (the performance level) in 10 stations in the training groups

\begin{tabular}{|c|c|c|c|c|c|}
\hline \multirow{2}{*}{$\begin{array}{l}\text { Educational groups } \\
\text { Evaluation station }\end{array}$} & \multicolumn{2}{|c|}{ Mean and Standard Deviation } & \multirow{2}{*}{$\begin{array}{l}T \\
\text { test }\end{array}$} & \multirow[t]{2}{*}{ Df } & \multirow[t]{2}{*}{ Sig } \\
\hline & Before Intervention & After Intervention & & & \\
\hline 1 Measuring blood pressure & $9.28 \pm 0.88$ & $8.80 \pm 0.797$ & 0.775 & 38 & 0.079 \\
\hline 2 Dressing change & $8.97 \pm 0.865$ & $8.15 \pm 1.40$ & 1.793 & 38 & 0.031 \\
\hline 3 Measuring body temperature & $8.25 \pm 1.99$ & $8.25 \pm 2.41$ & 0.481 & 38 & 0.972 \\
\hline 4 Colostomy care & $8.27 \pm 1.03$ & $8.24 \pm 0.554$ & 0.286 & 38 & 0.257 \\
\hline 5 Wound care clinical scenario & $7.95 \pm 1.60$ & $8.65 \pm 1.26$ & 1.300 & 38 & 0.134 \\
\hline 6- Clinical bowel care scenario & $7.57 \pm 1.97$ & $5.79 \pm 1.75$ & 3.016 & 38 & 0.005 \\
\hline 7- Pressure ulcer care & $9.87 \pm 0.55$ & $8.68 \pm 1.83$ & 2.769 & 38 & 0.052 \\
\hline 8- Oxygen therapy & $8.31 \pm 1.42$ & $7.56 \pm 1.48$ & 1.630 & 38 & 0.111 \\
\hline 9- Vital signs scenario & $7.99 \pm 1.85$ & 5.292 .48 & 3.890 & 38 & $<0.001$ \\
\hline 10- Identifying devices & $9.37 \pm 1.59$ & $8.37 \pm 3.03$ & 1.731 & 38 & 0.086 \\
\hline
\end{tabular}

by Liw et al. (2010) on first year nursing students in Singapore, which was conducted using the integrated training and problem- based training, the performance score of students who participated in the integrated education was higher than the performance score of those who received the problem- based training alone [18]. Lee et al. (2009) in Korea investigated the effectiveness of integrating two training methods (critical thinking strategies with simulation) on the empowerment in nursing fundamentals. The results suggested that the problem-solving skills and self-directed learning was significantly improved in the experimental group. Thus, the integrated method was proposed as a useful strategy in nursing education [19].

This study showed that the integration of critical thinking strategies (problem based learning with small group discussion) with simulation can improve the practical learning. The integration of both active learning will provide the opportunity to practice clinical skills in a real non-threatening environment [20, 21]. This helps students to have personal interpretation from problems and therefore strengthens the learning processes and problem-solving skill [22, 23]. In this research, students were given the opportunities to deeply discuss and explore the scenario through the integration of simulation and critical thinking strategies. The theoretical knowledge obtained from the scenario analysis facilitates

Table 6 Comparison between the mean and standard deviation of scores obtained in OSCE test (the performance level) in both groups

\begin{tabular}{llc}
\hline The performance level score & $\begin{array}{l}\text { Mean and } \\
\text { Standard } \\
\text { Eeviation }\end{array}$ & Sig \\
\hline Experimental group & $87.35 \pm 6.20$ & 0.0001 \\
Control group & $79.9 \pm 7.35$ & \\
\hline
\end{tabular}

the transfer of theoretical knowledge to students' clinical performance during simulation as well as encourages the discussion after simulation synthesis and application of the knowledge.

\section{Conclusion}

The findings of the present study suggest that the use of integrated training methods (simulations and critical thinking strategies) as an active learning and studentdirected strategies increase students' practical learning in a safe and controlled environment. This participatory approach is a deep learning guide for the learner in order to think aloud and explore the knowledge, solve problems and think critically.

Group dynamics on the development of critical debate and immersion in the simulation cycle enable students to use various sources to understand the functions (capabilities) of the job prospects while transferring knowledge. In addition, training in the stress-free environment of the clinical skills center enables coaches to allow students to obtain theoretical foundations and practical application of knowledge and problem-solving skills more. In this regard, it is recommended by researchers to use integrated teaching practices in the clinical training planning in order to enhance the clinical performance of students.

\section{Abbreviations}

OSCE: Objective Structured Clinical Examination; CCTST: California Critical Thinking Skills Test; KR-20: Kuder-Richardson formula 20

\footnotetext{
Acknowledgements

The present article was extracted from the MSc Medical Education thesis by Mrs. Farideh Saadat under the guidance of Dr. Nahid Zarif Sanaiey with the consultation of Dr. Mitra Amini (Grant No: 92-6673). The authors would like to thank the Vice-chancellor of Shiraz University of Medical Sciences for supporting this research. The authors also thank the Clinical Research Development Center of Shiraz University of Medical Sciences for the statistical analysis.
} 


\section{Funding}

No funding was provided for this work.

\section{Availability of data and materials}

The data that support the findings of this study are available from the corresponding author on request.

\section{Authors' contributions}

NZ devised the study concept, designed the study, supervised the intervention, data collection and analysis, participated in the coordination of the study, and critically revised the manuscript. MA collected data, ran the study intervention, participated in the study concept, performed the analyses and revised the manuscript. SF contributed to the design and analysis of the study data, and drafted the manuscript. All authors read and approved the final manuscript.

\section{Competing interests}

The authors declare that they have no competing interests.

\section{Consent for publication}

Not applicable.

\section{Ethics approval and consent to participate}

In this study, the following ethical issues were considered: After obtaining permission from the college officials, the training program began at the Clinical Skills Learning Center, Faculty of Nursing and Midwifery, Shiraz University of Medical Sciences. At the beginning of the training program after the researcher had introduced himself, he explained the objectives of the study and the need to implement them to the students and the written consent was obtained from students participating in the study. The students were also assured that all information collected will remain confidential.

This study was approved by the Ethics Committee of Shiraz University of Medical Sciences (ECSUMS). Approved Code of Ethics Committee for Research Project was CT-92-6673.

\section{Author details}

'Department of E-learning, Virtual School, Center of Excellence for e-Learning in Medical Sciences, Shiraz University of Medical Sciences, Shiraz, Iran. ${ }^{2}$ Quality improvement in clinical teaching Research Center, Education Development Center, Shiraz University of Medical Sciences, Sina- Sadra Halls Complex, Neshat Ave, Shiraz, Iran. ${ }^{3}$ Fatemeh (P.B.U.H) College of Nursing and Midwifery, Shiraz University of Medical Sciences, Shiraz, Iran.

Received: 10 June 2016 Accepted: 1 November 2016

Published online: 16 November 2016

\section{References}

1. Murphy S, Hartigan I, Walshe N, Flynn AV, O'Brien S. Merging problembased learning and simulation as an innovative pedagogy in nurse education. Clin Simul Nurs. 2011;7(4):e141-8.

2. Karamizadeh Z, Zarifsanayei N, Faghihi AA, Mohammadi H, Habibi M. The study of effectiveness of blended learning approach for medical training courses. Iranian Red Crescent Medical Journal. 2012 Jan;2012 (1, Jan):41-4

3. Deubel P. An investigation of behaviorist and cognitive approaches to instructional multimedia design. J Educ Multimedia Hypermedia. 2003; 12(1):63-90.

4. Billings DM, Halstead JA. Teaching in nursing: A guide for faculty. Elsevier Health Sciences; 2015 Oct 31

5. Husebø SI, Bjørshol CA, Rystedt H, Friberg F, Søreide E. A comparative study of defibrillation and cardiopulmonary resuscitation performance during simulated cardiac arrest in nursing student teams. Scand J Trauma Resusc Emerg Med. 2012;20:1-1.

6. Weaver A. High-Fidelity Patient Simulationin Nursing Education: An Integrative Review. Nurs Educ Perspect. 2011;32(1):37-40.

7. Lewis DY, Ciak AD. THE IMPACTof aSimulation Lab ExperienceforNursing Students. Nurs Educ Perspect. 2011;32(4):256-8.

8. Cooper S, Beauchamp A, Bogossian F, Bucknall T, Cant R, DeVries B, Endacott R, Forbes H, Hill R, Kinsman L, Kain VJ. Managing patient deterioration: a protocol for enhancing undergraduate nursing students' competence through web-based simulation and feedback techniques. BMC Nurs. 2012;11(1):1.
9. Walthew PJ. Conceptions of critical thinking held by nurse educators. J Nurs Educ. 2004:43(9):408-11.

10. Simpson E, Courtney M. Implementation and evaluation of critical thinking strategies to enhance critical thinking skills in Middle Eastern nurses. Int J Nurs Pract. 2008;14(6):449-54.

11. Kong LN, Qin B, Zhou YQ, Mou SY, Gao HM. . The effectiveness of problem-based learning on development of nursing students' critical thinking: A systematic review and meta-analysis. Int J Nurs Stud. 2014; 51(3):458-69.

12. Rowles CJ, Brigham C. Strategies to promote critical thinking and active learning. Teaching in nursing: A guide for faculty. 2005:2:283-315.

13. Carrick JA. Student Achievement and NCLEX-RN Success: Problems That Persist. Nurs Educ Perspect. 2011;32(2):78-83.

14. Kaddoura MA. Critical thinking skills of nursing students in lecture-based teaching and case-based learning. Learning. 2011:5(2):20.

15. Facione NC, Facione PA. The" california critical thinking skills test" and the national league for nursing accreditation requirement in critical thinking. ERIC Clearinghouse; 1994. Shinnick MA, Woo MA. The effect of human patient simulation on critical thinking and its predictors in prelicensure nursing students. Nurse Educ Today. 2013:33(9):1062-7.

16. Ravert P. Patient simulator sessions and critical thinking. J Nurs Educ. 2008:47(12):557-62.

17. Brown D, Chronister $C$. The effect of simulation learning on critical thinking and self-confidence when incorporated into an electrocardiogram nursing course. Clin Simul Nurs. 2009;5(1):e45-52.

18. Liaw SY, Chen FG, Klainin P, Brammer J, O'Brien A, Samarasekera DD. Developing clinical competency in crisis event management: An integrated simulation problem-based learning activity. Adv Health Sci Educ. 2010;15(3):403-13

19. Lee WS, Cho KC, Yang SH, Roh YS, Lee GY. Effects of problem-based learning combined with simulation on the basic nursing competency of nursing students. J Korean Acad Fundam Nurs. 2009;16(1):64-72.

20. Walshe N, O'Brien S, Murphy S, Hartigan I. Integrative learning through simulation and problem-based learning. Clin Simul Nurs. 2013;9(2):e47-54

21. Sohn M, Ahn Y, Lee M, Park H, Kang N. The problem-based learning integrated with simulation to improve nursing students' self-efficacy.

22. Moattari M, Moosavinasab E, Dabbaghmanesh MH, ZarifSanaiey N Validating a Web-based Diabetes Education Program in continuing nursing education: knowledge and competency change and user perceptions on usability and quality. J Diabetes Metab Disord. 2014; 13(1):1.

23. Kim JY, Choi EY. Learning element recognition and academic achievement of nursing student receiving PBL with simulation education. Korean J Adult Nurs. 2008:20(5):731-42.

\section{Submit your next manuscript to BioMed Central and we will help you at every step:}

- We accept pre-submission inquiries

- Our selector tool helps you to find the most relevant journal

- We provide round the clock customer support

- Convenient online submission

- Thorough peer review

- Inclusion in PubMed and all major indexing services

- Maximum visibility for your research

Submit your manuscript at www.biomedcentral.com/submit
Biomed Central 